Journal of Mathematics and Statistics 4 (4): 264-268, 2008

ISSN 1549-3644

(C) 2008 Science Publications

\title{
Numerical Solution of Fourth Order Linear Ordinary Differential Equations by Cubic Spline Collocation Tau Method
}

\author{
${ }^{1}$ O.A. Taiwo and ${ }^{2}$ O.M. Ogunlaran \\ ${ }^{1}$ Department of Mathematics, \\ Faculty of Science, University of Ilorin, Ilorin, Nigeria \\ ${ }^{2}$ Departments of Mathematics and Statistics, \\ Faculty of Science and Science Education, Bowen University, Iwo, Nigeria
}

\begin{abstract}
Problem Statement: Many boundary value problems that arise in real life situations defy analytical solution; hence numerical techniques are desirable to find the solution of such equations. New numerical methods which are comparatively better than the existing ones in terms of efficiency, accuracy, stability, convergence and computational cost are always needed. Approach: In this study, we developed and applied three methods-standard cubic spline collocation, perturbed cubic spline collocation and perturbed cubic spline collocation tau method with exponential fitting, for solving fourth order boundary value problems. A mathematical software MATLAB was used to solve the systems of equations obtained in the illustrative examples. Results: The results obtained, from numerical examples, show that the methods are efficient and accurate with perturbed cubic spline collocation tau method with exponential fitting been the most efficient and accurate method with little computational effort involved. Conclusion: These methods are preferable to some existing methods because of their simplicity, accuracy and less computational cost involved.
\end{abstract}

Key words: Collocation, max. error, perturbed equation, recurrence relation, chebyshev polynomial

\section{INTRODUCTION}

Fourth order boundary value problems occur in a number of areas of applied mathematics among which are fluid mechanics, elasticity and quantum mechanics as well as science and engineering. Only small class of differential equations can be solved by analytical methods. Hence, several authors have investigated some numerical techniques for solving boundary value problems, among which include cubic spline method, Ritz method, finite difference method, multi-derivative method and finite element method; see for instance $^{[3,6,8,10]}$

The general fourth-order boundary value problem considered is of the form:

$$
\begin{gathered}
y^{1 v}(x)+p(x) y^{\prime \prime \prime}(x)+q(x) y^{\prime \prime}(x)+r(x) y^{\prime}(x) \\
+s(x) y(x)=f(x), x_{0} \leq x \leq x_{n}
\end{gathered}
$$

with the boundary conditions:

$$
\delta_{1} \mathrm{y}_{0}^{\prime}+\xi_{1} \mathrm{y}_{\mathrm{o}}=\eta_{1}
$$

$$
\alpha_{2} y_{0}^{\prime \prime \prime}+\beta_{2} y_{0}^{\prime \prime}+\delta_{2} y_{0}^{\prime}+\xi_{2} y_{0}=\eta_{2}
$$

$\delta_{3} y_{n}^{\prime}+\xi_{3} y_{n}=\eta_{3}$

$\alpha_{4} y_{\mathrm{n}}^{\prime \prime \prime}+\beta_{4} \mathrm{y}_{\mathrm{n}}^{\prime \prime}+\delta_{4} \mathrm{y}_{\mathrm{n}}^{\prime}+\xi_{4} \mathrm{y}_{\mathrm{n}}=\eta_{4}$

where:

$\mathrm{p}, \mathrm{q}, \mathrm{r}, \mathrm{s}$ and $\mathrm{f}$ are smooth functions of $\mathrm{x}$

$\delta_{\mathrm{i}}, \alpha_{\mathrm{i}}, \beta_{\mathrm{i}}$ and $\xi$ are known constants

Derivation of governing equations: The cubic spline linear equation is given as follows:

$$
\begin{gathered}
\mathrm{S}^{\prime \prime}(\mathrm{x})=\left[\frac{\left(\mathrm{x}-\mathrm{x}_{\mathrm{i}-1}\right)}{\mathrm{h}}\right] \mathrm{M}_{\mathrm{i}}+\left[\frac{\left(\mathrm{x}_{\mathrm{i}}-\mathrm{x}\right)}{\mathrm{h}}\right] \mathrm{M}_{\mathrm{i}-1}, \\
\mathrm{x}_{\mathrm{i}-1} \leq \mathrm{x} \leq \mathrm{x}_{\mathrm{i}}
\end{gathered}
$$

where, $\mathrm{M}_{\mathrm{i}-1}=\mathrm{S}^{\prime \prime}\left(\mathrm{x}_{\mathrm{i}-1}\right), \quad \mathrm{M}_{\mathrm{i}}=\mathrm{S}^{\prime \prime}\left(\mathrm{x}_{\mathrm{i}}\right)$ and $\mathrm{h}=\mathrm{x}_{\mathrm{i}}-\mathrm{x}_{\mathrm{i}-1}$.

We rewrite (6) as: 
Where:

$$
I_{1}=\frac{\left(x-x_{i-1}\right)}{h} M_{i}
$$

And

$$
I_{2}=\frac{\left(x_{i}-x\right)}{h} M_{i-1}
$$

Integrating Eq. 8 and 9 with respect to $\mathrm{x}$, we obtain respectively:

$$
\mathrm{I}_{11}=\frac{\left(\mathrm{x}-\mathrm{x}_{\mathrm{i}-1}\right)^{2}}{2 \mathrm{~h}} \mathrm{M}_{\mathrm{i}}+\mathrm{c}_{\mathrm{i}}
$$

And

$$
I_{21}=\frac{\left(x_{i}-x\right)^{2}}{2 h} M_{i-1}+d_{i}
$$

Thus, (7) becomes:

$$
\begin{aligned}
S^{\prime}(x)=\frac{1}{h}\left[\frac{\left(x-x_{i-1}\right)^{2}}{2} M_{i}-\right. & \left.\frac{\left(x_{i}-x\right)^{2}}{2} M_{i-1}\right] \\
& +c_{i}+d_{i}
\end{aligned}
$$

Likewise, we have:

$$
\begin{aligned}
S(x)=\frac{1}{h}\left[\frac{\left(x-x_{i-1}\right)^{3}}{6}\right. & \left.M_{i}+\frac{\left(x_{i}-x\right)^{3}}{6} M_{i-1}\right] \\
& +c_{i}\left(x_{i}-x\right)+d_{i}\left(x-x_{i-1}\right)
\end{aligned}
$$

where, $c_{i}$ and $d_{i}$ are constants of integration to be determined. Thus collocating (11) at point $\mathrm{x}=\mathrm{x}_{\mathrm{i}-1}$ and $\mathrm{x}$ $=\mathrm{x}_{\mathrm{i}}$ respectively, we obtain:

$$
\mathrm{S}\left(\mathrm{x}_{\mathrm{i}-1}\right)=\frac{1}{\mathrm{~h}}\left[\frac{\mathrm{h}^{3}}{6} \mathrm{M}_{\mathrm{i}-1}\right]+\mathrm{hc}_{\mathrm{i}}
$$

And

$$
\mathrm{S}\left(\mathrm{x}_{\mathrm{i}}\right)=\frac{1}{\mathrm{~h}}\left[\frac{\mathrm{h}^{3}}{6} \mathrm{M}_{\mathrm{i}}\right]+\mathrm{hd}_{\mathrm{i}}
$$

Hence, making use of the above definitions, we can conveniently rewrite Eq. 12 and 13 as follows:

$$
c_{i}=\frac{1}{h}\left[y_{i-1} \frac{h^{2}}{6} M_{i-1}\right]
$$

And

$$
\mathrm{d}_{\mathrm{i}}=\frac{1}{\mathrm{~h}}\left[\mathrm{y}_{\mathrm{i}}-\frac{\mathrm{h}^{2}}{6} \mathrm{M}_{\mathrm{i}}\right]
$$

Thus substituting (14) and (15) in (11), we obtain:

$$
\begin{aligned}
S(x)= & \frac{1}{h}\left[\frac{\left(x-x_{i-1}\right)^{3}}{6} M_{i}+\frac{\left(x_{i}-x\right)^{3}}{6} M_{i-1}\right] \\
+ & \frac{1}{h}\left[y_{i-1}-\frac{h^{2}}{6} M_{i-1}\right]\left(x_{i}-x\right) \\
& +\frac{1}{h}\left[y_{i}-\frac{h^{2}}{6} M_{i}\right]\left(x-x_{i-1}\right)
\end{aligned}
$$

Hence, differentiating (16), we obtain:

$$
\begin{aligned}
S^{\prime}(x)= & \frac{1}{2 h}\left[\left(x-x_{i-1}\right)^{2} M_{i}-\left(x_{i}-x\right)^{2} M_{i-1}\right] \\
& +\frac{1}{h}\left[y_{i-1}-\frac{h^{2}}{6} M_{i-1}\right]+\frac{1}{h}\left[y_{i}-\frac{h^{2}}{6} M_{i}\right]
\end{aligned}
$$

Since $S$ " $(x)$ is continuous, collocating (17) at point $\mathrm{x}=\mathrm{x}_{\mathrm{i}-1}$ and moving in clockwise direction, we obtain:

$$
\begin{array}{r}
S^{\prime}\left(x_{i}-\right)=\frac{h}{3} M_{i}+\frac{h}{6} M_{i-1}+\frac{1}{h}\left(y_{i}-y_{i-1}\right), \\
i=1,2, \ldots, N
\end{array}
$$

Again collocating Eq. (17) at point $\mathrm{x}=\mathrm{x}_{\mathrm{i}-1}$ and moving in anti-clockwise direction, we obtain:

$$
\begin{array}{r}
\mathrm{S}^{\prime}\left(\mathrm{x}_{\mathrm{i}}+\right)=\frac{-\mathrm{h}}{3} \mathrm{M}_{\mathrm{i}}-\frac{\mathrm{h}}{6} \mathrm{M}_{\mathrm{i}+1}+\frac{1}{\mathrm{~h}}\left(\mathrm{y}_{\mathrm{i}+1}-\mathrm{y}_{\mathrm{i}}\right), \\
\mathrm{i}=0,1,2, \ldots . \mathrm{N}-1
\end{array}
$$

Thus, the comparison of (18) and (19) leads to the recurrence relation:

$$
\begin{array}{r}
M_{i-1}+4 M_{i}+M_{i-1}=\frac{6}{h^{2}}\left(y_{i-1}-2 y_{i}+y_{i+1}\right), \\
i=1,2,3, . ., N-1
\end{array}
$$

We can also work with $S^{\prime}(x)=m_{i}$, the Spline first derivatives. Therefore, combining (18) and (19) in appropriate manner, we obtain the recurrence relation for the $\mathrm{m}_{\mathrm{i}}$ :

$$
m_{i-1}+4 m_{i}+m_{i+1}=\frac{3}{h}\left(y_{i+1}-y_{i-1}\right.
$$

Differentiating (17), we obtain:

$$
\mathrm{S}^{\prime \prime}(\mathrm{x})=\frac{1}{\mathrm{~h}}\left[\left(\mathrm{x}-\mathrm{x}_{\mathrm{i}-1}\right) \mathrm{M}_{\mathrm{i}}+\left(\mathrm{x}_{\mathrm{i}}-\mathrm{x}\right) \mathrm{M}_{\mathrm{i}-1}\right]
$$

Collocating (22) at point $\mathrm{x}=\mathrm{x}_{\mathrm{i}-1}$, we have:

$$
\mathrm{S}^{\prime \prime}\left(\mathrm{x}_{\mathrm{i}}\right)=\mathrm{M}_{\mathrm{i}}
$$


Again by differentiating (22) once more, collocating at point $\mathrm{x}=\mathrm{x}_{\mathrm{i}-1}$ and moving in clockwise direction, we obtain:

$$
\mathrm{S}^{\prime \prime \prime}\left(\mathrm{x}_{\mathrm{i}}-\right)=\frac{1}{\mathrm{~h}}\left(\mathrm{M}_{\mathrm{i}}-\mathrm{M}_{\mathrm{i}-1}\right)
$$

Similarly, for anti-clockwise direction, we obtain:

$$
\mathrm{S}^{\prime \prime \prime}\left(\mathrm{x}_{\mathrm{i}}+\right)=\frac{1}{\mathrm{~h}}\left(\mathrm{M}_{\mathrm{i}+1}-\mathrm{M}_{\mathrm{i}}\right)
$$

\section{MATERIALS AND METHODS}

The descriptions of the three methods considered in this study are given as follows:

Standard Spline collocation Tau method: Here, we collocate (1) at the point $\mathrm{x}=\mathrm{x}_{\mathrm{i}-1}$ and then substitute (17)-(19) back into (1). After re-arranging and on carrying out all necessary simplifications, we obtain:

$$
\begin{aligned}
& \left(\frac{1}{h^{2}}-\frac{p\left(x_{i}\right)}{2 h}+\frac{1}{12} q\left(x_{i}\right)+\frac{h}{12} r\left(x_{i}\right)\right) M_{i-1}+\left(\frac{5}{6} q\left(x_{i}\right)-\frac{2}{h^{2}}\right) M_{i} \\
& +\left(\frac{1}{h^{2}}+\frac{p\left(x_{i}\right)}{2 h}+\frac{1}{12} q\left(x_{i}\right)-\frac{h}{12} r\left(x_{i}\right)\right) M_{i+1}+\frac{r\left(x_{i}\right)}{2 h} y_{i+1} \\
& \quad-\frac{r\left(x_{i}\right)}{2 h} y\left(x_{i-1}\right)+\operatorname{sy}\left(x_{i}\right)=f\left(x_{i}\right)
\end{aligned}
$$

where, $x_{i}=a+\frac{(b-a) i}{N}, i=1,2, \ldots . N-1$.

In general, equation (26) together with the four boundary conditions given by (2)-(5) and the recurrence relation given by $(20)$, constitute $2(\mathrm{~N}+1)$ algebraic equations in $2(\mathrm{~N}+1)$ unknowns. These $2(\mathrm{~N}+1)$ algebraic equations can be put in matrix form as $\mathrm{Ax}=$ $\mathrm{b}$, where, $\mathrm{A}$ is the coefficient matrix, $\mathrm{b}$ is the column vector and $\mathrm{x}$ is the column vector of the unknowns, which are then solved using a mathematical softwareMATLAB to obtain the unknown constants yi and Mi (i $=0,1, \ldots, \mathrm{N})$.

Perturbed Spline collocation Tau method: This method is aimed at improving the accuracy and efficiency of the standard collocation Tau method. Eq. 1 is slightly perturbed to give:

$$
\begin{aligned}
& y^{\prime \prime \prime \prime}(x)+p(x) y^{\prime \prime \prime}(x)+(x) y^{\prime \prime}(x)+r(x) y^{\prime}(x) \\
& +s(x) y(x)=f(x)+H_{N}(x), \quad x_{o} \leq x \leq x_{n}
\end{aligned}
$$

where, $\mathrm{H}_{\mathrm{N}}(\mathrm{x})=\tau_{1} \mathrm{~T}_{\mathrm{N}}(\mathrm{x})+\tau_{2} \mathrm{~T}_{\mathrm{N}-1}(\mathrm{x})$ and $\mathrm{T}_{\mathrm{N}}(\mathrm{x})$ is the Chebyshev polynomial of first kind of degree $\mathrm{N}$ defined by $\mathrm{T}_{\mathrm{N}}(\mathrm{x})=\cos \left[\mathrm{N} \cos ^{-1} \mathrm{x}\right],-1 \leq \mathrm{x} \leq 1$.
Following the same procedure under standard spline collocation Tau method, we obtain:

$$
\begin{aligned}
& \left(\frac{1}{h^{2}}-\frac{p\left(x_{i}\right)}{2 h}+\frac{1}{12} q\left(x_{i}\right)+\frac{h}{12} r\left(x_{i}\right)\right) M_{i-1}+\left(\frac{5}{6} q\left(x_{i}\right)-\frac{2}{h^{2}}\right) M_{i} \\
& +\left(\frac{1}{h^{2}}+\frac{p\left(x_{i}\right)}{2 h}+\frac{1}{12} q\left(x_{i}\right)-\frac{h}{12} r\left(x_{i}\right)\right) M_{i+1}+\frac{r\left(x_{i}\right)}{2 h} y_{i+1} \\
& \quad-\frac{r\left(x_{i}\right)}{2 h} y_{i-1}+s_{i}=f_{i}+\tau_{1} T_{N}\left(x_{i}\right)+\tau_{1} T_{N-1}\left(x_{i}\right)
\end{aligned}
$$

where, $x_{i}=a+\frac{(b-a) i}{N+2}, \quad i=1,2, \ldots . N+1$

In general, equation (28) together with the four boundary conditions given by (2) $-(5)$ and (20) constitute $2(\mathrm{~N}+3)$ equations in $2(\mathrm{~N}+4)$ unknowns. Therefore in order to have a complete system, we impose the end conditions:

$$
\begin{aligned}
M_{0} & =0 \\
M_{n} & =0
\end{aligned}
$$

The resulting $2(\mathrm{~N}+3)$ algebraic equations in $2(\mathrm{~N}+3)$ unknowns are then solved to obtain the unknown constants $\mathrm{yi}(\mathrm{i}=0,1, \ldots \mathrm{N}+2)$

Mi (i $=1,2, \ldots \mathrm{N}+1), \tau_{1}$ and $\tau_{2}$.

Perturbed Spline Collocation Tau method with exponential fitting: Eq. 1 is slightly perturbed to give:

$$
\begin{aligned}
& \mathrm{y}^{\prime \prime \prime \prime}(\mathrm{x})+\mathrm{p}(\mathrm{x}) \mathrm{y}^{\prime \prime \prime}(\mathrm{x})+(\mathrm{x}) \mathrm{y}^{\prime \prime}(\mathrm{x})+\mathrm{r}(\mathrm{x}) \mathrm{y}^{\prime}(\mathrm{x}) \\
& +\mathrm{s}(\mathrm{x}) \mathrm{y}(\mathrm{x})=\mathrm{f}(\mathrm{x})+\mathrm{F}_{\mathrm{N}}(\mathrm{x})
\end{aligned}
$$

where, $\mathrm{F}_{\mathrm{N}}(\mathrm{x})=\tau, \mathrm{T}_{\mathrm{N}}(\mathrm{x})$.

We now have the boundary conditions as:

$$
\begin{gathered}
\delta_{1} \mathrm{y}_{0}^{\prime}+\xi_{1} y_{0}+\tau_{2} \mathrm{e}^{\mathrm{x}_{0}}=\eta_{1} \\
\alpha_{2} \mathrm{y}_{0}^{\prime \prime \prime}+\beta_{2} \mathrm{y}_{0}^{\prime \prime}+\delta_{2} \mathrm{y}_{0}^{\prime}+\xi_{2} \mathrm{y}_{0}+\tau_{2} \mathrm{e}^{\mathrm{x}_{\mathrm{n}}}=\eta_{2} \\
\delta_{3} \mathrm{y}_{\mathrm{n}}^{\prime}+\xi_{3} \mathrm{y}_{\mathrm{n}}+\tau_{2} \mathrm{e}^{\mathrm{x}_{\mathrm{n}}}=\eta_{3} \\
\alpha_{4} \mathrm{y}_{\mathrm{n}}^{\prime \prime \prime}+\beta_{4} \mathrm{y}_{\mathrm{n}}^{\prime \prime}+\delta_{4} \mathrm{y}_{\mathrm{n}}^{\prime}+\xi_{2} \mathrm{y}_{\mathrm{n}}+\tau_{2} \mathrm{e}^{\mathrm{x}_{\mathrm{n}}}=\eta_{4}
\end{gathered}
$$

Following the same procedure under perturbed spline collocation Tau method, we obtain

$$
\begin{aligned}
& \left(\frac{1}{h^{2}}-\frac{p\left(x_{i}\right)}{2 h}+\frac{1}{12} q\left(x_{i}\right)+\frac{h}{12} r\left(x_{i}\right)\right) M_{i-1}+\left(\frac{5}{6} q\left(x_{i}\right)-\frac{2}{h^{2}}\right) M_{i} \\
& +\left(\frac{1}{h^{2}}+\frac{p\left(x_{i}\right)}{2 h}+\frac{1}{12} q\left(x_{i}\right)-\frac{h}{12} r\left(x_{i}\right)\right) M_{i+1}+\frac{r\left(x_{i}\right)}{2 h} y_{i+1} \\
& \quad-\frac{r\left(x_{i}\right)}{2 h} y_{i-1}+s y_{i}=f_{i}+\tau_{1} T_{n}\left(x_{i}\right)
\end{aligned}
$$


where, $x_{i}=a+\frac{(b-a) i}{N+2}, \quad i=1,2, \ldots . . N+1$.

In general, Eq. 36 together with the four boundary conditions given by Eq. $32-35$ and 20 constitute $2(\mathrm{~N}+3)$ Equations in 2(N+4) unknowns. Therefore in order to have a complete system, we impose the end conditions given by Eq. 29 and 30. The resulting 2(N+3) algebraic equations in $2(\mathrm{~N}+3)$ unknowns are then solved to obtain the unknown constants where, $\mathrm{y}_{\mathrm{i}}(\mathrm{i}=$ $0,1, \ldots, \mathrm{N}+2), \mathrm{M}_{\mathrm{i}}(\mathrm{i}=0,1, \ldots, \mathrm{N}+1)$.

\section{RESULTS}

Carrying out all the analysis involve for each of the methods discussed above on some specific problems with selected uniform values of $\mathrm{N}(4,6,8$ and 10$)$, we show the results of the problems considered.

We define our error estimate in all cases as:

$$
\text { Error }=\operatorname{x}_{0} \operatorname{Max}_{x}<x_{n}|Y(x)-y(x)|
$$

\section{Example 1:}

$$
\begin{array}{ll}
\text { Solve } & y^{\text {iv }}(x)-y(x)=0 \\
& y(0)=1, \quad y^{\prime}(0)=1 \\
& y^{\prime}(1)-y(1)=0, y^{\prime \prime}(1)-y(1)=0
\end{array}
$$

The analytical solution is:

$$
y(x)=\exp (x)
$$

\section{Example 2:}

$$
\begin{gathered}
\text { Solve } \mathrm{y}^{\prime \prime \prime}(\mathrm{x})-3601 \mathrm{y}^{\prime \prime}(\mathrm{x})+3600 \mathrm{y}(\mathrm{x})=-1+1800 \mathrm{x}^{2} \\
\mathrm{y}(0)=1.0 ; \mathrm{y}(1)=1.5+\sinh (1) \\
\mathrm{y}^{\prime}(0)=1.0 ; \mathrm{y}^{\prime}(1)=1.0+\cosh (1)
\end{gathered}
$$

The analytical solution is

$$
y(x)=1+1 / 2 x^{2}+\sinh (x)
$$

\section{DISCUSSION}

Tables 1 and 2 show the numerical solutions in terms of the maximum errors obtained for the problems considered. It is observed that the perturbed collocation Tau method with exponential fitting converges faster than the standard and the perturbed collocation Tau methods.

The perturbed collocation Tau method and exponential fitting collocation Tau method involve large matrix system of equations of the same degree. It
Table 1: Max error for example 1

\begin{tabular}{llll}
\hline Method/ & $\begin{array}{l}\text { Standard } \\
\text { collocation } \\
\text { Tau method }\end{array}$ & $\begin{array}{l}\text { Perturbed } \\
\text { collocation } \\
\text { Tau method }\end{array}$ & $\begin{array}{l}\text { Exponential } \\
\text { fitting } \\
\text { Tau method }\end{array}$ \\
\hline 4 & $5.363021 \mathrm{E}-05$ & $6.521463 \mathrm{E}-07$ & $4.204866 \mathrm{E}-08$ \\
6 & $1.202621 \mathrm{E}-05$ & $2.085333 \mathrm{E}-07$ & $1.287704 \mathrm{E}-09$ \\
8 & $4.049993 \mathrm{E}-06$ & $7.083514 \mathrm{E}-08$ & $4.055816 \mathrm{E}-10$ \\
10 & $1.721575 \mathrm{E}-06$ & $2.213888 \mathrm{E}-08$ & $3.780911 \mathrm{E}-10$ \\
\hline
\end{tabular}

Table 2: Max error for example 2

\begin{tabular}{llll}
\hline Method/ & $\begin{array}{l}\text { Standard } \\
\text { collocation } \\
\text { Tau method }\end{array}$ & $\begin{array}{l}\text { Perturbed } \\
\text { collocation } \\
\text { Tau method }\end{array}$ & $\begin{array}{l}\text { Exponential } \\
\text { fitting } \\
\text { Tau method }\end{array}$ \\
\hline 4 & $2.518238 \mathrm{E}-07$ & $3.185140 \mathrm{E}-08$ & $1.825102 \mathrm{E}-09$ \\
6 & $7.257185 \mathrm{E}-08$ & $2.861825 \mathrm{E}-10$ & $2.868296 \mathrm{E}-11$ \\
8 & $2.666267 \mathrm{E}-08$ & $3.815309 \mathrm{E}-10$ & $1.024003 \mathrm{E}-12$ \\
10 & $1.175959 \mathrm{E}-08$ & $1.001205 \mathrm{E}-11$ & $1.005006 \mathrm{E}-13$ \\
\hline
\end{tabular}

is interesting to compare the accuracy and the computational cost involved. In Table 1 for example, for the case $\mathrm{N}=4$ the two methods involve $14 \times 14$ systems of algebraic equations with maximum errors of 6.521463E-07 and 4.204866E-08 respectively, while the standard collocation Tau method involves $10 \times 10$ systems of algebraic equations with maximum error of 5.363021E-05. Exponentially fitting collocation Tau method converges faster in all cases as the value of $\mathrm{N}$ increases at no extra computational cost when compared with the other two methods.

We observed that the perturbed collocation Tau method and exponential fitting collocation Tau method described in this paper are more efficient and accurate than parameter expansion method proposed by Taiwo in $^{[8]}$ and quintic and sextic Spline methods proposed by Usmani in ${ }^{[11]}$.

\section{CONCLUSION}

Standard cubic spline collocation tau method, perturbed cubic spline collocation tau method and exponential fitting collocation tau method have been showed for solving fourth order boundary value problem. Numerical examples have also been used to demonstrate the efficiency and accuracy of the methods.

\section{REFERENCES}

1. Ahlberg, J.H., E.N. Nilson and J.L. Walsh, 1967. The theory of spline and their applications. Academic Press, New York. ISBN: 0120447509.

2. Al-said E.A., and M.A. Noor, 2006. Cubic spline method for solving fourth order obstacle problems. Applied Math. Computation, 174: 180-187. DOI: 10.1016/j.amc.2005.03.022 
3. Burden, R.L. and J.D. Faires, 2001. Numerical Analysis, 7th Edn., Brooks Cole, Pacific, Grove, ISBN: 0534382169.

4. Lancoz, C., 1956. Applied Analysis, 1st Edn., Prentice Hall, New Jersey. ISBN: 10:048665656X.

5. Oritz, E.L., 1968. The tau method. SIAM J. Numerical Analysis, 6: 480-492. http://dx.doi.org/10.1137/0706044.

6. Sakai, M. and R. Usmani, 1983. Spline Solutions for nonlinear fourth order two-point boundary value problems. Publi. Res. Math. Sci., 19: 135-144.

http://projecteuclid.org/DPubS? service=UI\&v ersion $=1.0 \&$ verb $=$ Display $\&$ handle $=$ euclid.pri $\mathrm{ms} / 1195182980$

7. Taiwo, O.A. and D.J. Evans, 1997. Collocation approximation for fourth order boundary value problems. Int. J. Comput. Math., 63: 57-66.

DOI: $10.1080 / 00207169708804551$.
8. Taiwo, O.A., 1995. A parameter expansion method for two-point non linear singularly perturbed boundary value problems. J. Comput. Math., 55: 189-196. DOI: 10.1080/00207169508804374

9. Taiwo, O.A., 2002. Exponential fitting for the solution of two-point boundary value problems with cubic spline collocation tau method. Int. J. Comput. Math., 79: 229-306. DOI: 10.1080/00207160211929.

10. Taiwo, O.A., 2005. Comparison of Collocation methods for the solution of second order non linear boundary value problems. Int. J. Comp. Maths., 82: 1389-1402. DOI: 10.1080/00207160410001661645.

11. Usmani, R.A., 1980. Smooth spline approximations for the solution of a boundary value problem with engineering applications. J. Comput. Appl. Math., 6: 93-98. 